\title{
Generating Isolated Outputs in a Multilevel Modular Capacitor Clamped DC-DC Converter (MMCCC) for Hybrid Electric and Fuel Cell Vehicles
}

\author{
Faisal H. Khan ${ }^{1}$, Leon M. Tolbert ${ }^{2}$ \\ ${ }^{1}$ Electric Power Research Institute (EPRI) \\ 942 Corridor Park Blvd. \\ Knoxville, TN 37932 \\ Email: fkhan@epri.com \\ ${ }^{2}$ The University of Tennessee \\ Department of Electrical Engineering and Computer Science \\ Knoxville, TN 37996-2100 \\ Email: tolbert@utk.edu
}

\begin{abstract}
This paper presents a new technique to obtain isolated de voltage outputs from a capacitor clamped dc-dc converter. The multilevel modular capacitor clamped converter (MMCCC) has several key features that make it possible to generate ac outputs $(10 \mathrm{kHz})$ from a dc-dc converter circuit. Using those high frequency ac outputs, the MMCCC circuit can incorporate single or multiple high frequency transformers to generate isolated ac outputs. These isolated outputs can be rectified and filtered to obtain unidirectional or bi-directional de outputs. Using another MMCCC converter stage or an active full bridge block, the ac port can be made bi-directional to transfer power in both directions. By adopting the MMCCC topology to achieve isolated outputs, it is possible to simultaneously integrate multiple de sources in an isolated and non-isolated manner. This paper will investigate the origin of the ac outputs in the MMCCC circuit, and present an analytical approach to estimating the isolated dc output voltage. Finally, experimental results will be presented for further verification of the concept.
\end{abstract}

\section{INTRODUCTION}

Capacitor clamped dc-dc converters have many features that are advantageous over the other topologies of dc-dc converters based on inductive energy transfer method (IETM) such as buck, boost, and buck-boost converter. The key advantage of the capacitive energy transfer method is the high efficiency operation that is an inherent nature of the circuit topology.

However, one of the advantageous features of the wellknown IETM converters is the scope of achieving isolated dc outputs using a high frequency transformer [1$3]$. This isolation is essential when the converter needs to be integrated between a low voltage bus and a high voltage bus. However, the conventional capacitorclamped circuits do not offer isolated outputs, and this paper will show how it can be achieved from the multilevel modular capacitor clamped converter (MMCCC).

\section{NEED FOR ISOLATION}

In future hybrid electric or fuel cell automobiles, a bidirectional dc-dc converter is an integral part of the multivoltage dc architecture. This dc-dc converter maintains a power balance between the fuel cell and any energy storage inside the vehicle, and provides continuous power to the drive train [4]. A new topology of multilevel dc-dc converter was shown in [5] that maintain a power balance between a $250 \mathrm{~V}$ and a $42 \mathrm{~V}$ system. However, there are still $12 \mathrm{~V}$ (or $14 \mathrm{~V}$ ) loads in the vehicle, and another isolated dc-dc converter is required to establish an energy balance between the $42 \mathrm{~V}$ and $14 \mathrm{~V}$ buses. Because many consumer appliances may be connected to the $14 \mathrm{~V}$ bus, it should be electrically isolated from the high voltage bus [6-7].

A solution to this problem would be using a second dc-dc converter that builds the power flow path between the $42 \mathrm{~V}$ and $14 \mathrm{~V}$ buses and creates necessary isolation. However, the use of two dc-dc converters involves substantial cost and complexity in the system, and it may not be possible to achieve a compact form factor for automobile applications. Here the proposed converter could possibly eliminate the need of the second stage and combines the two dc-dc conversion steps. Thereby, it is possible to generate isolated $12 \mathrm{~V}$ output from the new design without sacrificing various advantageous features of the MMCCC converter [8].

\section{ISOLATED MMCCC}

The original MMCCC converter had several advantageous features to be used in automotive applications. Multiple load-source integration was one of the key features of the MMCCC circuit [9]. Thus, the modular structure of the MMCCC converter was used to generate high frequency ac outputs to create isolated dc outputs. The modified version of the MMCCC converter having isolation is shown in Fig. 1. 


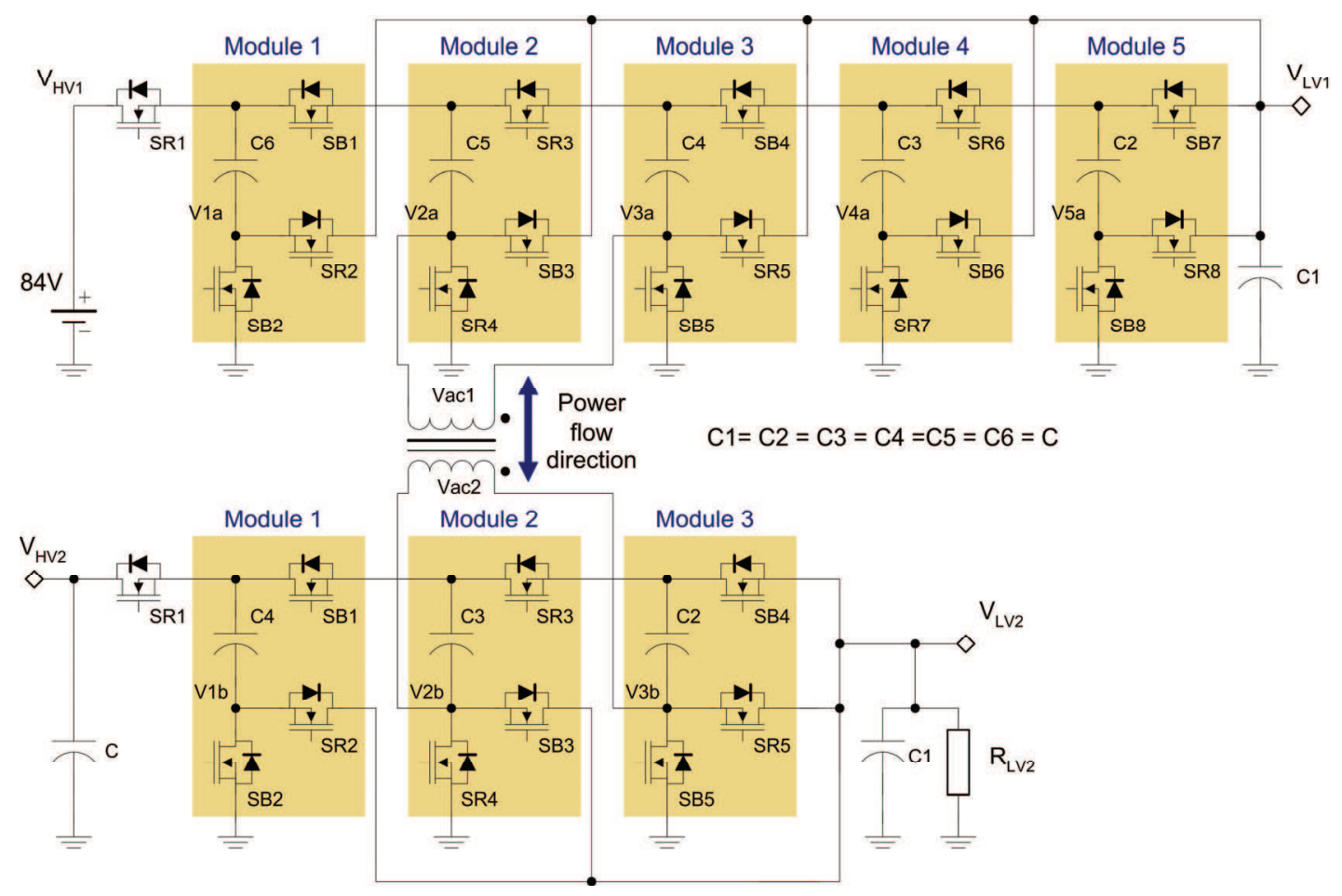

Fig. 1. Integration of a transformer in the dual MMCCC circuit.

It was shown in [10] how the MMCCC converter can generate high frequency ac outputs. This property is used to combine two MMCCC circuits with a transformer to provide coupling between the two circuits. In Fig. 1, circuit 1 shown on top is a 6-level MMCCC converter establishing the energy balance between the $84 \mathrm{~V}$ and 14 $\mathrm{V}$ bus. Circuit 2 shown in the bottom is a 4-level MMCCC circuit that has three modules. For proper operation, various sub-intervals of both the circuits should be synchronized. This includes a use of a common clock circuit to drive both MMCCC blocks in a synchronized way.

The various advantages of the isolated version of the MMCCC are not limited to the circuit shown in Fig. 1. Rather, there are many ways to generate isolated dc outputs from the original MMCCC converter. Fig. 2(a) shows another approach where the MMCCC converter is coupled to a full bridge stage to create an isolated bidirectional de port. This bridge circuit could adopt pulse width modulation (PWM) and various conversion ratios can be generated from the hybrid architecture. Fig. 2(b) shows a simpler solution where the isolated ac outputs are rectified to dc voltage by simply adding a passive rectifier stage. This version has only unidirectional power transfer operation.

Fig. 3 shows another approach where the circuit adopts a special transformer winding and can take advantage of the various ac nodes available in the MMCCC circuit. By virtue of the center-tap, the circuit used full wave rectification using only two diodes. This technique is favored by the lower voltage drop across the rectifier stage, and can achieve lower power loss.

The isolated version of MMCCC shown in Fig. 1 has many advantages over the three configurations shown in Fig. 2 and Fig. 3. In Fig. 1, the circuit constructs a power management system among various sources and loads by virtue of the MMCCC's multi load/source feature [9]. Thus, it is possible to connect multiple voltage sources and loads at various nodes of the 6-level MMCCC side and the 4-level MMCCC side. The topology shown in Fig. 2(a) allows the integration of only one source and one load at the H-bridge side of the converter. The configurations shown in Fig. 2(b) and Fig. 3 allow one way power transfer from the MMCCC side to the passive

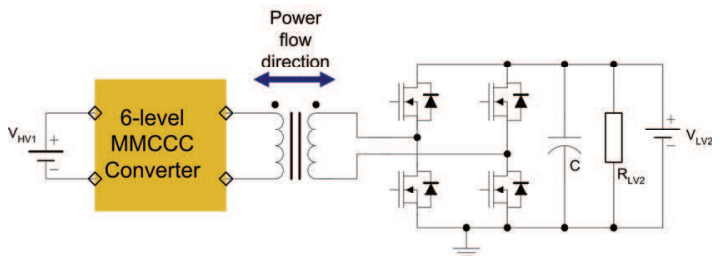

(a)

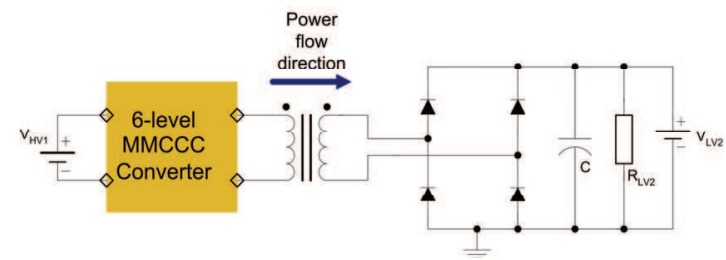

(b)

Fig. 2. Alternative ways to achieve isolated dc outputs from the MMCCC converter. (a) using full bridge, (b) using diode rectifier. 


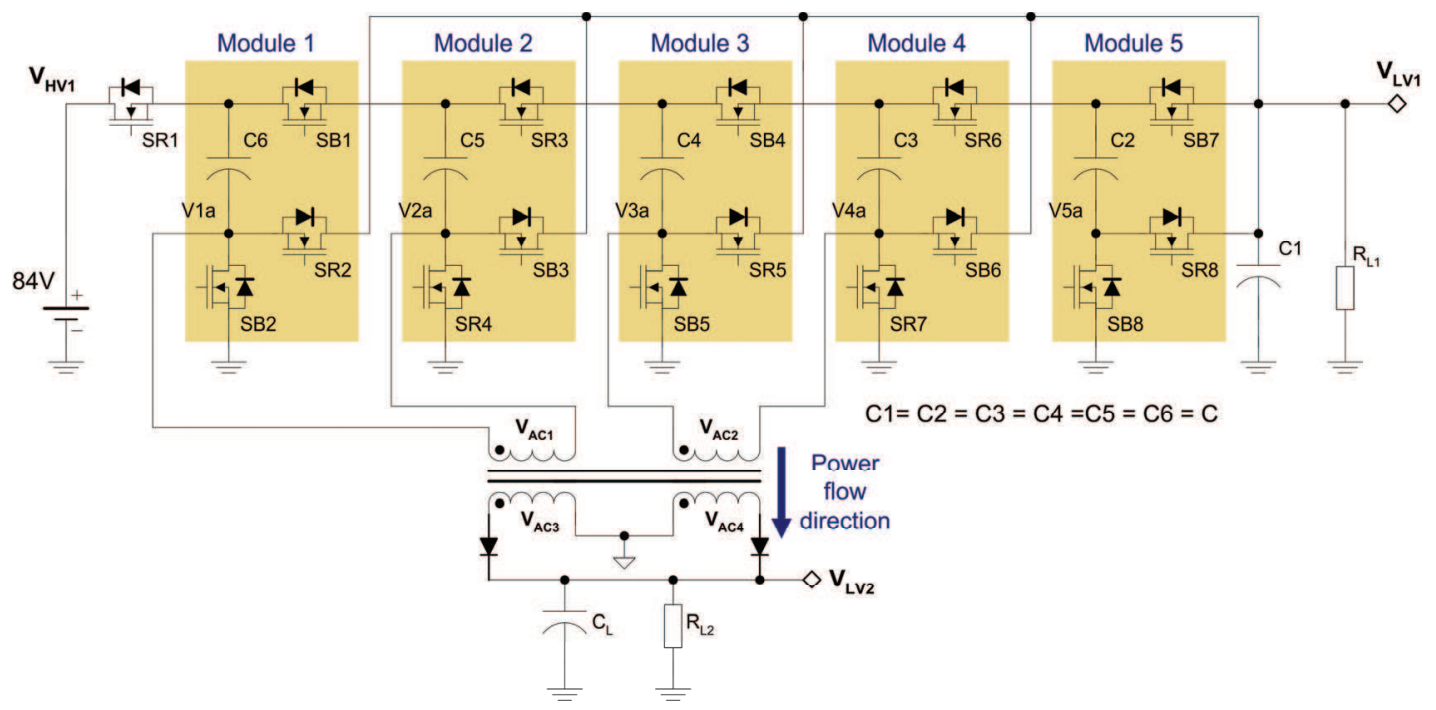

Fig. 3. Isolated MMCCC with passive secondary stage.

rectifier side. However, these two circuits should offer lower cost and higher efficiency compared to the circuits shown in Fig. 1 and Fig. 2(a).

\section{CIRCUIT CONSTRUCTION AND OPERATION}

Although the MMCCC circuit is a dc-dc converter, it can also produce ac outputs having frequency equal to the switching frequency of the converter. It was shown in [10] how the MMCCC can generate ac outputs with amplitude close to $1 \mathrm{~V}_{\mathrm{LV}}$ between two ac nodes in the MMCCC converter, and this amplitude is independent of the conversion ratio (CR) of the circuit. Thus, if a transformer of turns ratio $1: 1$ is connected across the ac terminals of the MMCCC circuit, and another MMCCC circuit is connected at the other terminals of the transformer, this pair of MMCCC circuits forms a bidirectional architecture that allows the integration of loads in isolated and non-isolated manner.

In Fig. 1, when an $84 \mathrm{~V}$ source is connected at $\mathrm{V}_{\mathrm{HV} 1}$, it is possible to produce non-isolated voltage of $14 \mathrm{~V}$ at $\mathrm{V}_{\mathrm{LV} 1}$, an isolated voltage of amplitude $14 \mathrm{~V}$ at $\mathrm{V}_{\mathrm{LV} 2}$ and an isolated $56 \mathrm{~V}$ output at $\mathrm{V}_{\mathrm{HV} 2}$ in no-load condition. In the same way, if a voltage source of amplitude $56 \mathrm{~V}$ is connected at $\mathrm{V}_{\mathrm{HV} 2}$, it is possible to achieve non-isolated $14 \mathrm{~V}$ output at $\mathrm{V}_{\mathrm{LV} 2}$, an isolated $14 \mathrm{~V}$ output at $\mathrm{V}_{\mathrm{LV} 1}$, and an isolated $84 \mathrm{~V}$ output at node $\mathrm{V}_{\mathrm{HV} 1}$ in no-load condition.

The MMCCC circuit has two switching state subintervals, and in each sub-interval, approximately one half of the transistors are ON. The timing diagram of the MMCCC circuit is shown in Fig. 4, and the corresponding equivalent circuit diagram for a 4-level MMCCC is shown in Fig. 5. For the simplicity of the analysis, it is assumed that power is flowing from the 4 level MMCCC to the 6-level converter side. During state 1 in a 4-level MMCCC circuit (shown in Fig. 1), all the SRx transistors are $\mathrm{ON}$ and all the $\mathrm{SBx}$ transistors are OFF. Thus, the voltage at V2b is zero (0), and the voltage at $\mathrm{V} 3 \mathrm{~b}$ is $\mathrm{V}_{\mathrm{LV} 2}$ during this interval. In the same way, the voltage at $\mathrm{V} 2 \mathrm{~b}$ is $\mathrm{V}_{\mathrm{LV} 2}$, and it is zero (0) at $\mathrm{V} 3 \mathrm{~b}$ during the second sub-interval. Thus, the voltage difference across $\mathrm{V} 2 \mathrm{~b}$ and $\mathrm{V} 3 \mathrm{~b}$ is $\pm \mathrm{V}_{\mathrm{LV} 2}$ or $\pm \mathrm{V}_{\mathrm{C} 1}$. If the expression of the voltage $\mathrm{V}_{\mathrm{C} 1}$ is found for these two sub-intervals, it is possible to determine the voltage across the transformer in steady state condition.

When a transformer is used in a dc-dc converter circuit,
Transition 2

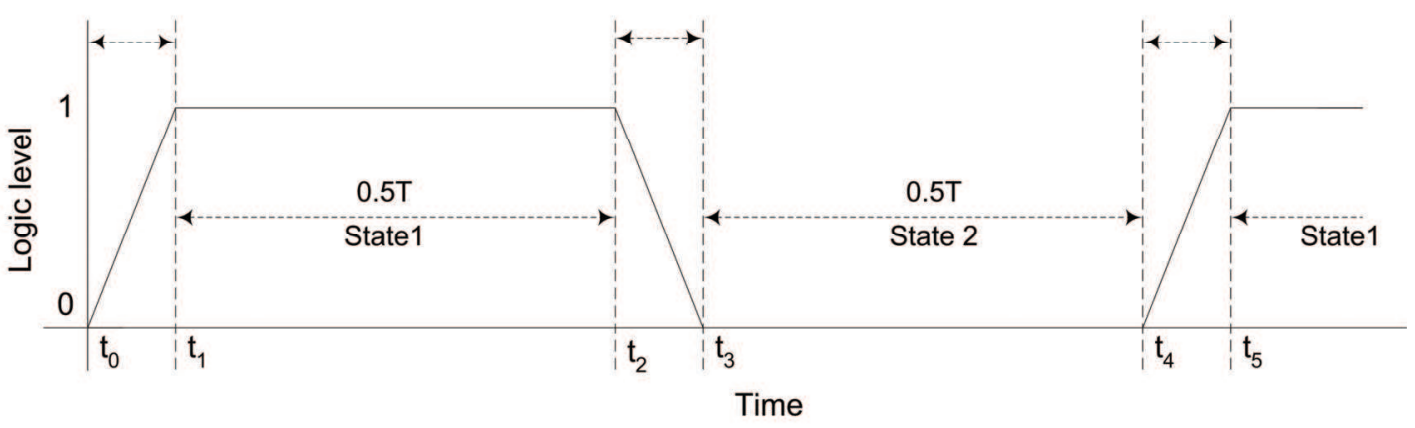

Fig. 4. Timing diagram and logic sequences in a 4-level MMCCC converter. 


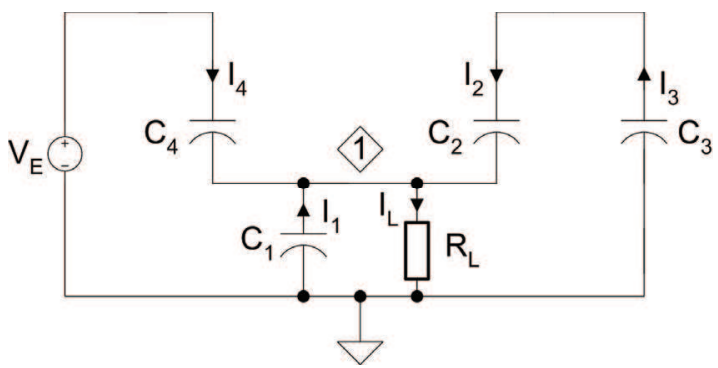

(a) subinterval 1

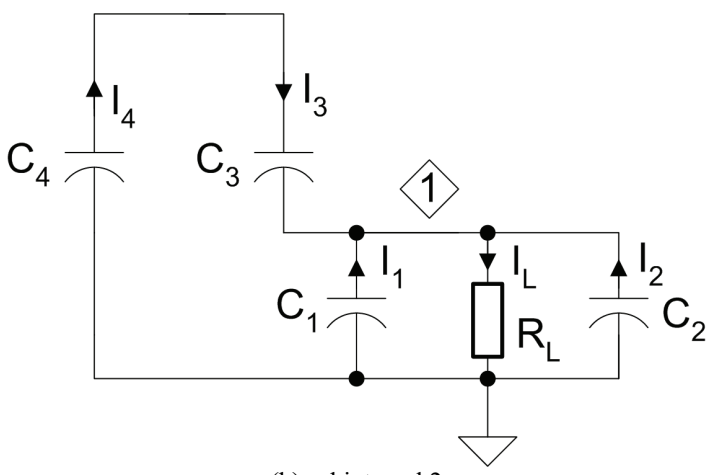

(b) subinterval 2

Fig. 5. Equivalent operational circuit of a 4-level MMCCC converter in each sub-interval.

the volt-second balance inside the transformer must be confirmed to ensure no residual flux build-up inside the transformer. In an H-bridge circuit, this balance is done by clamping the voltage of the primary winding to input dc voltage in both sub-intervals. The volt-second areas in positive and negative half cycles are balanced by clamping the voltage to $\pm 1 \mathrm{~V}_{\mathrm{LV}}$ in the MMCCC converter.

\section{Simulation Results}

To verify the concept of the new configuration, the schematic shown in Fig. 3 was simulated in PSIM. Two ideal single winding transformers were used in the simulations. $1000 \mu \mathrm{F}$ capacitors were used inside the MMCCC converter, and a $4700 \mu \mathrm{F}$ was used as $\mathrm{C}_{\mathrm{L}}$. Two $2 \Omega$ resistive loads were used as $R_{L 1}$ and $R_{L 2}$. The $R_{D S}$ of the MOSFETs used in the prototype (IRFI540N) were used in the simulation, and this value was $0.052 \Omega$. The transformer turns ratio was 12:13.

The circuit in Fig. 3 was simulated to find the voltages at $V_{L V 1}$ and $V_{L V 2}$ for no-load and at $2 \Omega$ loading conditions. In addition, the ac voltages $\mathrm{V}_{\mathrm{ACl}}, \mathrm{V}_{\mathrm{AC} 2}, \mathrm{~V}_{\mathrm{AC} 3}$, and $\mathrm{V}_{\mathrm{AC} 4}$ were also simulated. Fig. 6(a) shows the noload voltages at $\mathrm{V}_{\mathrm{LV} 1}$ and $\mathrm{V}_{\mathrm{LV} 2}$. Because of a turns ratio higher than $1, V_{L V 2}$ was slightly higher than $V_{L V 1}$. For an excitation of $84 \mathrm{~V}, \mathrm{~V}_{\mathrm{LV} 1}$ was $14 \mathrm{~V}(84 \div 6)$, and $\mathrm{V}_{\mathrm{LV} 2}$ was $15.17 \mathrm{~V}$. When $2 \Omega$ loads were connected at $\mathrm{V}_{\mathrm{LV} 1}$ and $\mathrm{V}_{\mathrm{LV} 2}$, voltages at these terminals dropped due to the voltage drop across MOSFETs, capacitors, and rectifier diodes at the secondary side. During this time, the average voltage at $\mathrm{V}_{\mathrm{LV} 1}$ was $13.21 \mathrm{~V}$, and mean $\mathrm{V}_{\mathrm{LV} 2}$ was 13.51 V. These voltages are shown in Fig. 6(b).

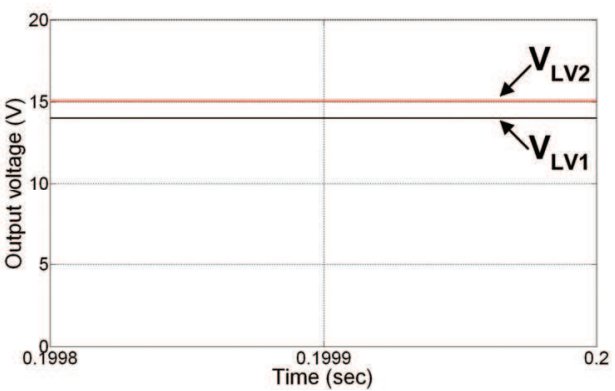

(a)

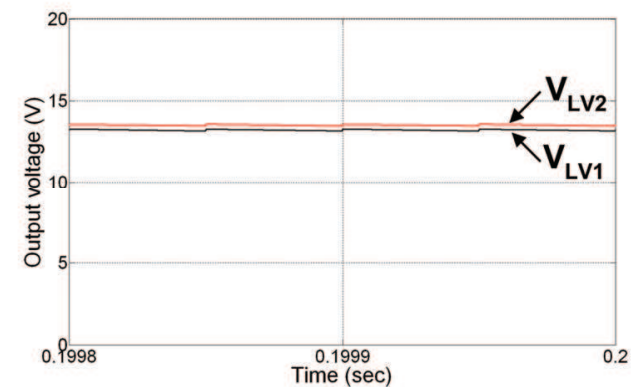

(b)

Fig. 6. Simulated voltages at $\mathrm{V}_{\mathrm{LV} 1}$ and $\mathrm{V}_{\mathrm{LV} 2}$ nodes at no-load and loaded conditions. (a) voltages at no-load condition, (b) voltages when $2 \Omega$ loads were connected at these terminals.

Voltages at the primary and secondary side of the transformer were also simulated for loaded condition. Fig. 7(a) shows the primary side voltages, and Fig. 7(b) shows the secondary side voltages. Because the turns ratio was slightly greater than 1 , secondary side voltages

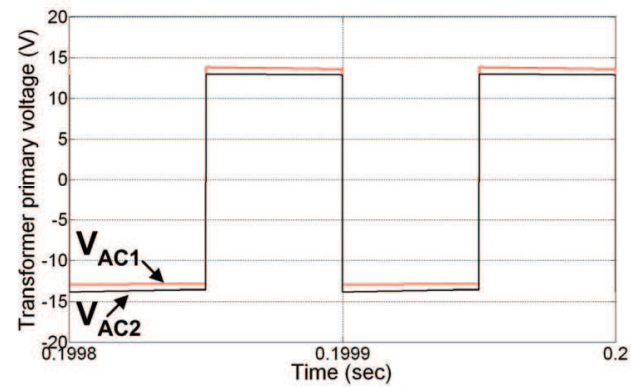

(a)

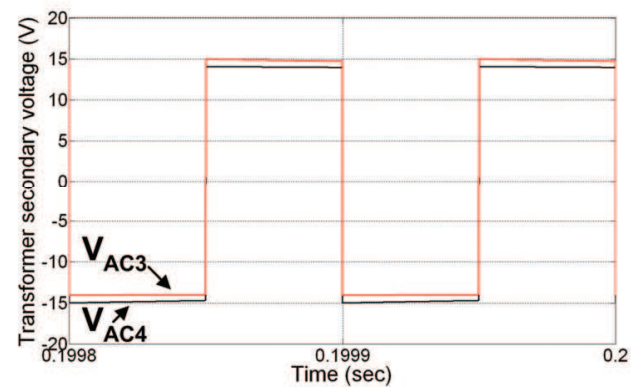

(b)

Fig. 7. Simulated results of the transformer voltages at loaded condition. (a) primary side voltages $\mathrm{V}_{\mathrm{AC} 1}$ and $\mathrm{V}_{\mathrm{AC} 2}$, (b) secondary side voltages $\mathrm{V}_{\mathrm{AC} 3}$ and $\mathrm{V}_{\mathrm{AC} 4}$. 
were higher than the primary side voltage by the same ratio. The voltages across the transformer had small negative slope that indicates the decaying voltage across the clamp capacitors inside the MMCCC converter.

\section{EXPERIMENTAL RESULTS}

A $500 \mathrm{~W}$ 6-level MMCCC converter was modified to achieve isolated dc outputs. A ferrite core transformer with 12 turns in each primary winding and 13 turns in each secondary winding were used. Ultra fast Si Schottky diodes were used as rectifier diodes at the secondary side. The values of the various components were consistent with the simulation set up. The experimental set up is shown in Fig. 8.

Fig. 9(a) and (b) shows the no-load and loaded condition output voltages at $\mathrm{V}_{\mathrm{LV} 1}$ and $\mathrm{V}_{\mathrm{LV} 2}$. The measured $\mathrm{V}_{\mathrm{LV} 1}$ was close to value found in the simulation $(14 \mathrm{~V})$. However, the secondary side voltage was 16.33 $\mathrm{V}$, which is higher than the simulated value of $15.17 \mathrm{~V}$. This may happen because of any offset present in the differential probe used to measure the voltage or any imperfections in the transformer construction. Fig. 9(b) shows the experimental results when $2 \Omega$ resistive loads were connected at the output terminals. Voltages measured at $\mathrm{V}_{\mathrm{LV} 1}$ and $\mathrm{V}_{\mathrm{LV} 2}$ were $12.40 \mathrm{~V}$ and $13.08 \mathrm{~V}$ respectively.

Fig. 10(a) and (b) shows the measured ac voltages across the primary and secondary windings of the transformer. Because of the decaying voltage across the capacitors, the primary side voltages of the transformer had a slightly negative slope, and a similar wave shape was found in the simulation. From the experimental waveforms, it can be observed that the average value of primary side voltages were zero (avg. of $\mathrm{V}_{\mathrm{AC} 1}+$ avg. of $\mathrm{V}_{\mathrm{AC} 2}$ ). This is true for the secondary side also.

The configuration shown in Fig. 1 was also constructed and experimentally tested. A 6-level MMCCC and a 4level MMCCC converter was used to prove the bidirectional power transfer mechanism between the converter modules. A high frequency ferrite core transformer made with 18 turns on the 6-level MMCCC side and 19 turns on the 4-level MMCCC side was used. An $84 \mathrm{~V}$ source was connected at $\mathrm{V}_{\mathrm{HV} 1}$ and a $5 \Omega$ resistive load was connected at $\mathrm{V}_{\mathrm{LV} 2}$. Thus, the entire system was tested in no-load and partial load condition. The circuit's switching frequency was $10 \mathrm{kHz}$.

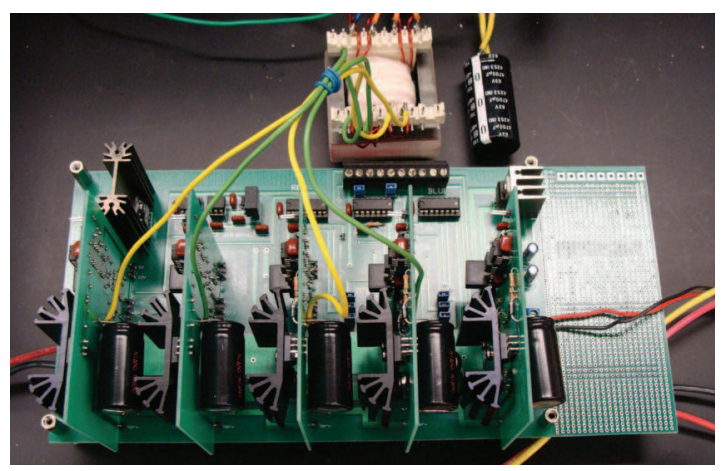

Fig. 8. Modified MMCCC setup to generate isolated dc outputs.

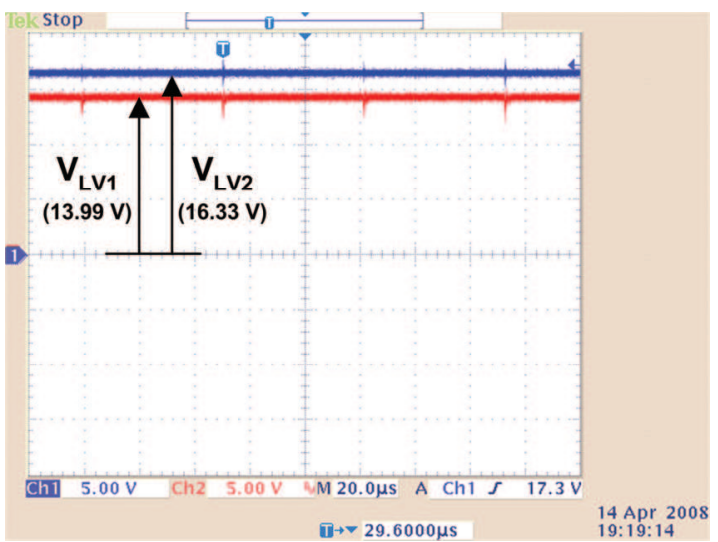

(a)

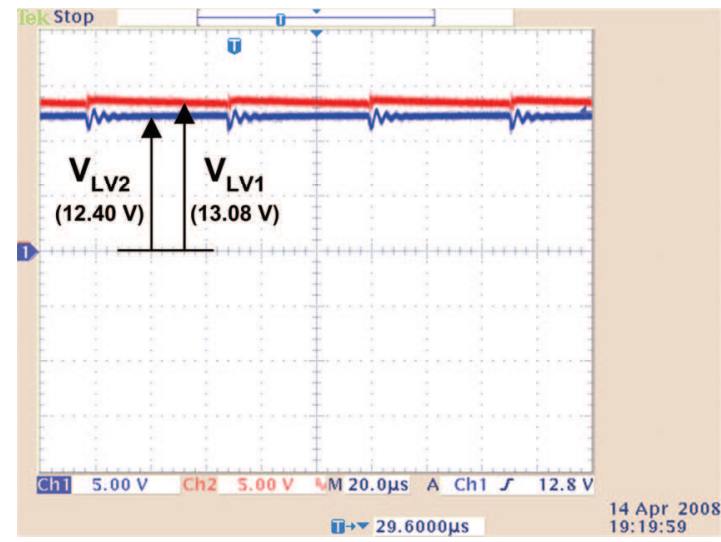

(b)

Fig. 9. Experimental results of the output de voltages at $V_{L V 1}$ and $\mathrm{V}_{\mathrm{LV} 2}$. (a) voltages at no-load condition, (b) voltages when $2 \Omega$ loads were connected at these terminals.

The circuit was tested by measuring the generated ac voltage at the secondary side of the transformer labeled as Vac2 in Fig. 1. Fig. 11(a) shows the voltage Vac2 at noload condition, and the voltage amplitude was $13.8 \mathrm{~V}$. When a $5 \Omega$ load was connected at the $\mathrm{V}_{\mathrm{LV} 2}$ node, it drew some current, and initiated the discharging operation across the capacitors in the 4-level MMCCC circuit. During this time, Vac2 is shown in Fig. 11(b). This figure is similar to Fig. 7 and Fig. 10 for the 6-level configurations.

\section{ANALYTICAL VERIFICATION}

The start up dynamic modeling and steady state analysis of a 4-level MMCCC converter has been presented in [11], and capacitor voltages at various time instants can be found from that analysis. The ac voltage swing produced at the MMCCC converter is actually the potential difference across two adjacent capacitors' negative terminals, and this is shown in Fig. 1. The equivalent circuits of a 4-level MMCCC circuit in its subintervals are shown in Fig. 5. Fig. 5(a) shows the equivalent circuit during sub-interval 1, and Fig. 5(b) shows that for second sub-interval. In the first subinterval, the negative terminal of $\mathrm{C}_{2}$ is clamped to $\mathrm{V}_{\mathrm{C} 1}$ and that of $\mathrm{C}_{3}$ is connected to ground. Thus, the voltage 


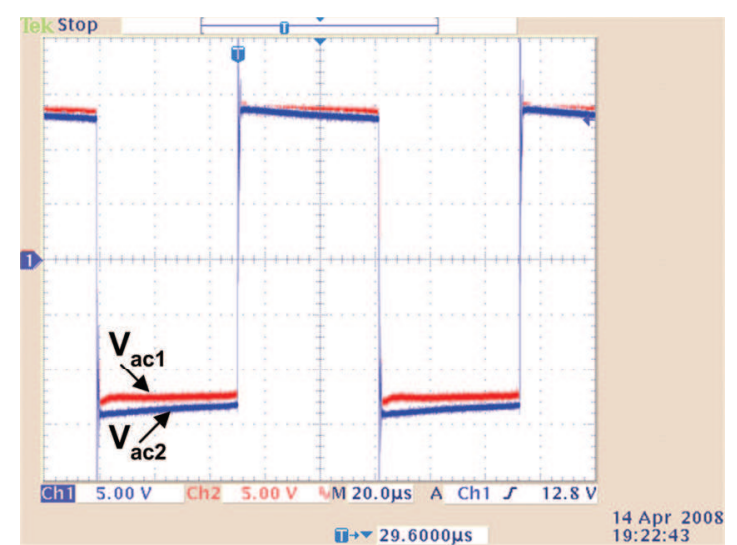

(a)

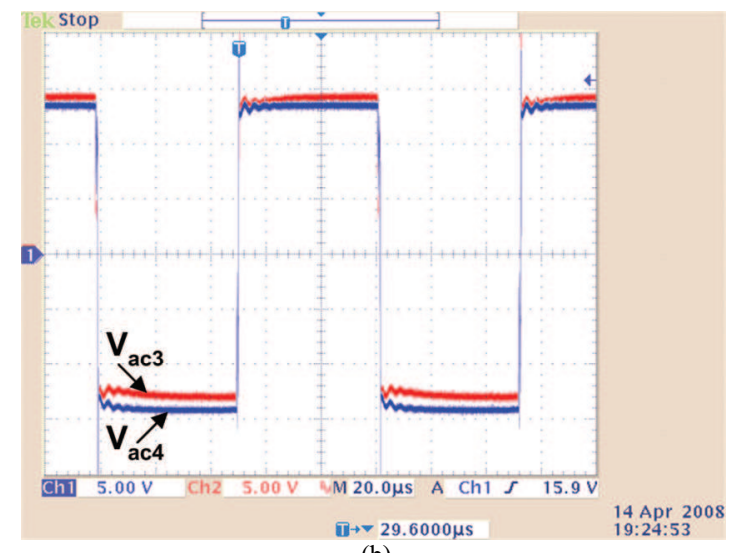

(b)

Fig. 10. Experimental results of the transformer voltages at loaded condition. (a) primary side voltages $\mathrm{V}_{\mathrm{AC} 1}$ and $\mathrm{V}_{\mathrm{AC} 2}$, (b) secondary side voltages $\mathrm{V}_{\mathrm{AC} 3}$ and $\mathrm{V}_{\mathrm{AC} 4}$.

produced between $\mathrm{V}_{\mathrm{C} 3}$ and $\mathrm{V}_{\mathrm{C} 2}$ terminals is $-\mathrm{V}_{\mathrm{C} 1}$. In the same way, this voltage is $\mathrm{V}_{\mathrm{C} 1}$ during the second subinterval, and the circuit orientation is shown in Fig. 5(b). Thus, the generated ac voltage between two adjacent nodes is $\pm \mathrm{V}_{\mathrm{Cl}}$. Now if the time varying voltage expression of $\mathrm{V}_{\mathrm{C} 1}$ can be found, the ac voltage swing of

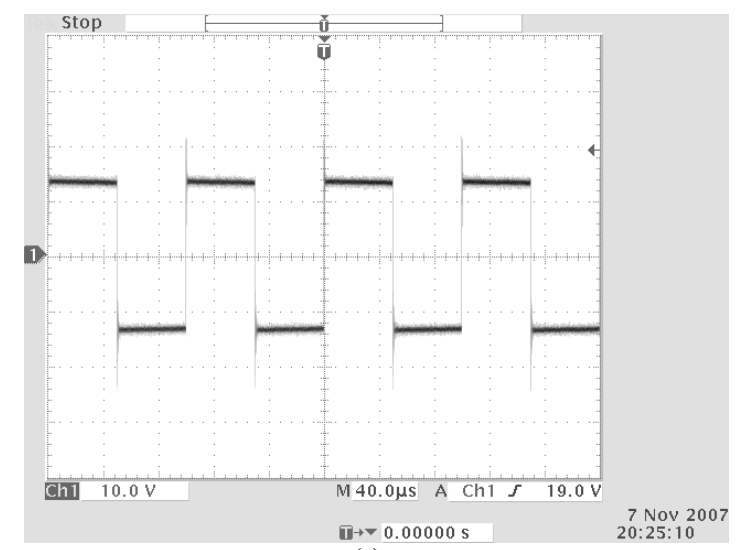

(a) the MMCCC can be modeled for various loading conditions.

When loads are connected to the circuit, the capacitor voltages will depend on the load current. Using the analysis presented in [11], voltages deduced for different time instants in a full operating cycle can be obtained. According to [11],

$$
\begin{aligned}
& V_{C 1}(t 1)=0.25 E+\delta 1 . \\
& V_{C 1}(t 2)=0.25 E+\delta 1-0.2 \Delta . \\
& V_{C 1}(t 3)=V_{C 2}(t 3)=0.25 E+0.2 \delta_{2}+0.02 \Delta \\
& V_{C 1}(t 4)=0.25 E+0.2 \delta_{2}-0.18 \Delta .
\end{aligned}
$$

where $\Delta=\frac{I_{L} \bullet T}{C}, I_{L}$ is the load current, and $E=V_{H V 2}$.

Now, $\delta 1=\frac{\Delta}{80}, \delta_{2}=-\frac{3 \Delta}{80}$.

Using (1) and (5), $V_{C 1}\left(t_{1}\right)=-\left(0.25 E+\frac{\Delta}{80}\right)$

Using (2) and (5),

$V_{C 1}\left(t_{2}\right)=0.25 E+\frac{\Delta}{80}-0.2 \Delta=-\left(0.25 E-\frac{3 \Delta}{16}\right)$

Using (3) and (5),

$V_{C 1}(t 3)=V_{C 2}(t 3)=0.25 E+0.2 \cdot \frac{3 \Delta}{16}+0.02 \Delta=\left(0.25 E+\frac{\Delta}{80}\right)$

Using (4) and (5),

$V_{C 1}(t 4)=0.25 E+0.2 \cdot \frac{3 \Delta}{16}-0.18 \Delta=\left(0.25 E-\frac{3 \Delta}{16}\right)$

The time instants $\left(t_{1}\right.$ to $\left.t_{4}\right)$ used in this calculation are synchronized with the timing diagram shown in Fig. 4, and the analytically computed value of $\mathrm{Vac} 2$ or (V2b $\mathrm{V} 3 \mathrm{~b}$ ) for a 4-level configuration at different time instants are shown in Fig. 12 using (6) to (9).

\section{CONCLUSIONS}

A new circuit design to obtain isolated bi-directional

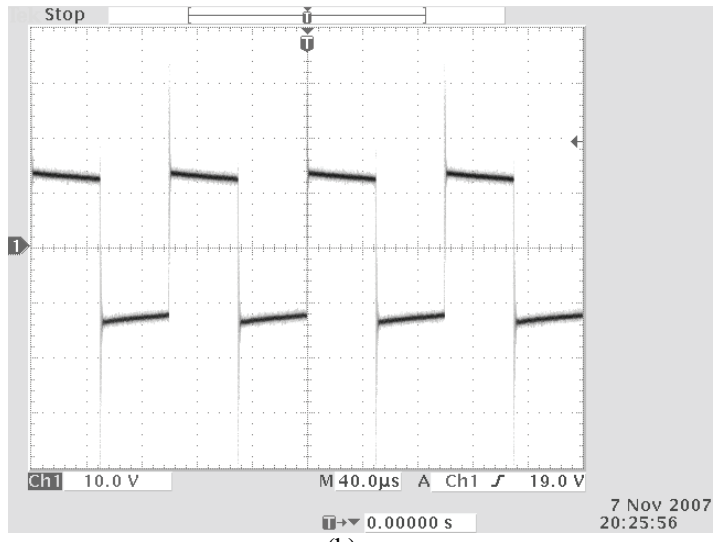

(b)

Fig. 11. Generated ac output voltage Vac2 of the secondary side of the transformer shown in Fig. 1. (a) no-load condition, (b) when a $5 \Omega$ load was connected at $\mathrm{V}_{\mathrm{LV} 2}$. 


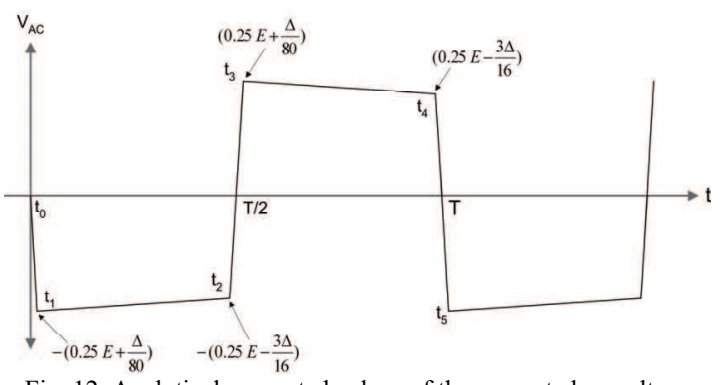

Fig. 12. Analytical computed values of the generated ac voltage $\mathrm{Vac} 2$ at various time instants. Here $\mathrm{V}_{\mathrm{AC}}=\mathrm{Vac} 2=\mathrm{V}_{\mathrm{C} 2}$.

dc-outputs from a capacitor-clamped dc-dc converter (MMCCC) has been proposed and the concept has been verified using analytical and experimental results. The experimental results show that isolated dc voltage outputs can be generated from one part of the circuit when connecting a voltage source in the other part, and these two parts are interlinked through a high frequency transformer.

Using a transformer with a turn ratio other than $1: 1$, it is possible to generate many other voltage levels. This paper has shown four possible configurations to generate isolated dc voltages. However, it is possible to deduce many other configurations using single or multi winding transformers with bridge or center-tap configurations. Thus, this isolated version of MMCCC could be adopted for various applications where multiple loads and sources need to be connected and isolation is necessary.

\section{REFERENCES}

[1] L. Tang, G. J. Su, "An Interleaved, Reduced Component Count, Multi-Voltage Bus DC/DC Converter For Fuel Cell Powered Electric Vehicle Applications," IEEE Industry Applications Society Annual Meeting, 2007, pp. 616-621.
[2] H. Li, F. Z. Peng, J. S. Lawler, "A Natural ZVS Medium-Power Bidirectional DC-DC Converter with Minimum Number of Components," IEEE Transactions on Industry Applications, vol. 39, no.2, pp. 525-535.

[3] L. M. Tolbert, W. A. Peterson, C. P. White, T. J. Theiss, M. B. Scudiere, "A bi-directional DC-DC converter with minimum energy storage elements," IEEE Applied Power Electronics Conference (APEC), Oct. 2002, pp. 1572-1577.

[4] Emadi, S. Williamson, A. Khaligh, "Power Electronics Intensive Solutions for Advanced Electric, Hybrid Electric, and Fuel Cell Vehicular Power Systems," IEEE Trans. of Power Electronics, vol. 21, no. 3, pp. 567-577, May 2006.

[5] F. H. Khan, L. M. Tolbert, "A 5-kW Multilevel DC-DC Converter for Future Hybrid Electric and Fuel Cell Automotive Applications," IEEE Industry Applications Society (IAS) Annual Meeting, 2007, pp. 628-635.

[6] John. G. Kassakian, David J. Perreault, "The Future of Electronics in Automobiles," Proceedings of $13^{\text {th }}$ International Symposium on Power Semiconductor Devices \& ICs, pp. 15-19, June 2001.

[7] John. G. Kassakian, "Automotive Electrical Systems - The Power Electronics Market of the Future," IEEE/APEC, vol. 1, pp. 3-9, Feb. 2000.

[8] F. Khan, L. M. Tolbert, "A Multilevel Capacitor-Clamped DC-DC Converter," IEEE Transactions on Industry Applications, vol. 43, no. 6 , pp. $1628-1638$

[9] F. H. Khan, L. M. Tolbert, "Multiple Load-Source Integration in a Multilevel Modular Capacitor Clamped DC-DC Converter Featuring Fault Tolerant Capability," IEEE Applied Power Electronics Conference (APEC), Feb. 2007, pp. 361-367.

[10] F. H. Khan, L. M. Tolbert, "A 5 kW Bi-directional Multilevel Modular DC-DC Converter (MMCCC) Featuring Built in Power Management for Fuel Cell and Hybrid Electric Automobiles," IEEE Vehicle Power and Propulsion Conference (VPPC), 2007.

[11] F. H. Khan, "Modular DC-DC Converters," Ph.D. thesis, The University of Tennessee, April 2007. 